\title{
Abu Zenima synthetic zeolite for removing iron and manganese from Assiut governorate groundwater, Egypt
}

\author{
Abd El Hay Ali Farrag' ${ }^{1}$ Th. Abdel Moghny ${ }^{3}$ Atef Mohamed Gad Mohamed ${ }^{2}$. \\ Saleem Sayed Saleem ${ }^{2} \cdot$ Mahmoud Fathy $^{3}$
}

Received: 26 February 2016/ Accepted: 23 May 2016/Published online: 8 June 2016

(c) The Author(s) 2016. This article is published with open access at Springerlink.com

\begin{abstract}
Groundwater in Upper Egypt especially in Assiut Governorate is considered the second source of fresh water and used for drinking, agriculture, domestic and industrial purposes. Unfortunately, it is characterized by high concentrations of iron and manganese ions. The study aimed at synthesizing zeolite-4A from kaolinite for removing the excess iron and manganese ions from Assiut Governorate groundwater wells. Therefor, the kaolinite was hydrothermally treated through the metakaolinization and zeolitization processes to produce crystalline zeolite4A. The chemical composition of crystalline zeolite-4A and its morphology were then characterized using X-ray diffraction (XRD) and scanning electron microscopy (SEM). Then the column experiments were conducted to study the performance of crystalline salt- $4 \mathrm{~A}$ as ion exchange and investigate their operating parameters and regeneration conditions. Thomas and Yoon-Nelson models were applied to predict adsorption capacity and the time required for $50 \%$ breakthrough curves. The effects of initial concentrations of 600 and $1000 \mathrm{mg} \mathrm{L}^{-1}$ for $\mathrm{Fe}^{2+}$ and $\mathrm{Mn}^{2+}$, feed flow rate of $10-30 \mathrm{ml} / \mathrm{min}$, and height range of $0.4-1.5 \mathrm{~cm}$ on the breakthrough behavior of the adsorption system were determined. The obtained results indicated that the synthesized zeolite-A4 can remove iron
\end{abstract}

Mahmoud Fathy

fathy8753@yahoo.com

1 Assiut University Faculty of Science Geology Department, Asyut, Egypt

2 Assiut and New Valley Company for Water and Waste Water, Asyut, Egypt

3 Applications Department, Egyptian Petroleum Research Institute (EPRI), 1 Ahmed El-Zomer, Nasr City, Box. No. 11727, Cairo, Egypt and manganese ions from groundwater to the permissible limit according to the standards drinking water law.

Keywords Groundwater · Abu Zenima kaolin · Synthetic zeolite $\cdot$ Metakaolinitization $\cdot$ Zeolitization $\cdot$ Assiut $\cdot$ Egypt

\section{Introduction}

Groundwater is the second source water used for drinking and agriculture in all Villages of Assiut Governorate. It is considered the main source for newly reclaimed areas in Wadi El-Assiuti and Western Desert. Many workers investigate the role and impacts of evaporation and mixing processes upon the groundwater quality in Assiut area. Understanding such processes as well as the hydrological conditions of the aquifers enable the proper management strategies and utilization of the groundwater resources Korany et al. (2013). According to the latest Assiut Drinking Water Company report, about $70 \%$ of the total Assiut wells contain very high concentrations of iron and manganese ions. The chemical character of groundwater is influenced by the minerals and gases reacting with water in its relatively slow excursion through the rocks and sediments. There are two sources of iron and manganese in the groundwater including the Geogesic and anthropogenic sources. The first source is where the groundwater in the aquifer passes through soils, sands, gravels and rocks. Hence, the iron and manganese content can be dissolved and go back to the groundwater. The anthropogenic sources include industrial effluents, landfill leakages, acid mine drainage, etc. leading to a high iron and manganese concentration in groundwater (Obiri-Nyarko et al. 2015).

Well casing, pump parts, piping and storage tank can also contribute iron and manganese to groundwater. From 
the above-mentioned facts, higher concentrations of iron and manganese in water cause many technological problems including failure of water supply systems' operation and water quality deterioration. Water with slightly higher concentrations of oxygen forms undesirable incrustations that result in the reduction of pipe flow cross-section (AlHobaib et al. 2016).

The conventional oxidation followed by filtration is the most effective water treatment method used to remove iron and manganese ions when their ratios exceed $10 \mathrm{mg} / \mathrm{L}$. Before iron and manganese can be filtered, they need to be oxidized to a state in which they can form insoluble complexes (Antunes et al. 2016). In this method it is necessary to install an activated carbon filter to remove the objectionable taste and odor from the residual chlorine. Hence, too little permanganate will not oxidize all the iron and manganese besides the fact that permanganate is expensive and leaving water with pink coloration (Zhang et al. 2016).

Removal of iron and manganese from groundwater for domestic use and for drinking water purposes using aerobic oxidation is a difficult and lengthy process and is not satisfactory in many cases for the following reasons: (1) it is difficult to complete the oxidation process to remove both ions at the same water conditions due to the different $\mathrm{pH}$ required to oxidize iron and manganese. (2) The growth of iron bacteria on sand filters or valves, cause water discoloration and increases its turbidity (Oliveira Barud et al. 2015; Shankar and Rhim 2015). Therefore, ion exchange method is considered one of the most promising methods for removing iron and manganese ions from the groundwater, as their concentration does not exceed $5 \mathrm{mg} / \mathrm{L}$ (Bilal et al. 2013; Yang et al. 2015).

The main target of this work was to remove the excess iron and manganese ions from Assiut Governorate groundwater wells using synthesized zeolite-4A as ion exchange.

\section{Materials and method}

\section{Materials}

1. Groundwater samples were taken from about 800 groundwater wells producing drinking water covering all Assiut Governorate in years 2010-2015 to identify the most contaminated wells.

2. Naturally occurring crystalline kaolin was used for the synthesis of zeolite.

3. Sorted sandstone with grain size of $0.7-1.2 \mathrm{~mm}$ was used as a filter in packed column.

\section{Methods and procedures}

Preparation of zeolite $4 A$

Zeolite-4A was synthesized through metakaolinization and zeolitization. Metakaolinization targeted the thermal activation of kaolin, while zeolitization involved alkaline attack of the thermally activated amorphous kaolin (metakaolin) and its transformation into crystalline Zeolite4A. In this respect, Abu zenima kaolin was crushed and sieved to $>80$ microns (Obiri-Nyarko et al. 2015). After that, kaolin was calcined at $800{ }^{\circ} \mathrm{C}$ for $5 \mathrm{~h}$ to convert kaolin to metakaolin. Then, the resulting metakaolin was grained, sieved to $<80$ micron. A mixture of metakaolin powder with sodium hydroxide solution at ratio of $1 \mathrm{~g}: 5 \mathrm{ml}$ was left for $24 \mathrm{~h}$ at room temperature following Ozekmekci et al. (2015). The reaction mixture was agitated at $100{ }^{\circ} \mathrm{C}$ for $4 \mathrm{~h}$. Then the mixture was filtered and washed with distilled water to remove the excess alkalis, decanted and filtered several times till the $\mathrm{pH}$ reaches 10.5, then dried at $90{ }^{\circ} \mathrm{C}$ overnight and ground to the particle size of $<80$ micron (Russo et al. 2015).

\section{Column study}

Two filters setups were prepared from the plastic P.V.C tubes, each of $5 \mathrm{~cm}$ inner diameter and $12 \mathrm{~cm}$ height. The used filter contained sorted sand $(0.7-1.2 \mathrm{~mm})$ and synthetic zeolite $(<0.8 \mathrm{~mm})$ with mixing ratio of $1: 1$. The filtration rate was adjusted to three steps using constant filtration media $(58 \mathrm{~g})$, the first at $10 \mathrm{~mL} / \mathrm{min}$, the second at $20 \mathrm{~mL} / \mathrm{min}$ and the third at $30 \mathrm{~mL} / \mathrm{min}$. Then the filtration media was reduced to the half for the three filtration rate. The concentration of $\mathrm{Fe}^{2+}$ and $\mathrm{Mn}^{2+}$ besides other physical parameters was analyzed before and after the treatment, every $\mathrm{ml}$ sequentially. After filtration, the ion concentrations of the aqueous phase were measured spectrophotometrically (model Jenway 6705) following the method of Zheng et al. (2015b).

\section{Results and discussion}

\section{Characterization}

The chemical composition of zeolite was determined using a Bruker S4 wavelength X-ray dispersive fluorescence spectrometer (WDXRFS), with a Rh X-ray tube. The zeolite morphology was characterized by a scanning electron microscope (SEM) at $20 \mathrm{kV}$ (JEOL JSM-6390A model). 


\section{XRD analysis}

The XRD pattern of the synthesized zeolite-4A shown in Fig. 1 exhibits characteristic zeolite-4A peaks at $2 \theta$ values of $7.2^{\circ}, 10.3^{\circ}, 12.6^{\circ}, 16.2^{\circ}, 21.8^{\circ}, 24^{\circ}, 26.2^{\circ}, 27.2^{\circ}, 30^{\circ}$, $30.9^{\circ}, 31.1^{\circ}, 32.6^{\circ}, 33.4^{\circ}$ and $34.3^{\circ}$. Similar observations were obtained by Ortiz-Iniesta and Melián-Cabrera (2015) who synthesized zeolite- $4 \mathrm{~A}$ at $3 \mathrm{M} \mathrm{NaOH}$. The obtained XRD pattern shows crystalline $\mathrm{SiO}_{2}$ besides hydroxysodalite $\left(13.96,19.98^{\circ}, 24.42^{\circ}\right.$, and 35.00$)$. The same results were obtained by Loiland and Lobo (2015).

\section{SEM analysis}

It is known that the framework structure of zeolite is described as a combination of two interconnected channel systems. SEM micrographs of kaolinite prior to treatment, after calcination and the final synthesized zeolite-4A are shown in Fig. 2a-c. Figure 2a shows the SEM micrograph of kaolinite before calcination or any treatment as tetrahedral sheets of clay mineral without negative charge, whereas SEM image of kaolinite after calcinations, Fig. 2b, shows the complete dehydroxylation of the kaolin and formation of a poorly crystalline metakaolin (amorphous metakaolin). Finally, Fig. 2c shows the SEM image of the synthesized zeolite 4A crystals after treatment by $\mathrm{NaOH}$ and illustrated the presence of agglomerated cubic crystals in the sample, indicating the presence of marked change that took place in the morphology of the starting materials. The cubic crystalline morphology typically of the zeolitic products obtained consisting of sinusoidal channels (along) with a circular cross section interconnected with straight channels (along) of elliptic cross section (5.3 $\mathrm{A} \times 5.6 \AA$ ) .

\section{Studies of contact time}

The initial $\mathrm{Fe}^{2+}$ and $\mathrm{Mn}^{2+}$ ion concentrations in flowing water under this study are 600 and $1000 \mathrm{mg} \mathrm{L}^{-1}$, respectively. Figures 3 and 4 show the influence of contact time on the adsorption of $\mathrm{Fe}^{2+}$ and $\mathrm{Mn}^{2+}$ by zeolite $4 \mathrm{~A}$ from raw water containing of $600 \mathrm{mg} \mathrm{L}^{-1} \mathrm{Fe}^{2+}$ and $1000 \mathrm{mg} \mathrm{L}^{-1} \mathrm{Mn}^{2+}$. These figures show that the initial adsorption was rapid within $100 \mathrm{~min}$ due to the adsorption of $\mathrm{Fe}^{2+}$ and $\mathrm{Mn}^{2+}$ onto the exterior surface. Then the metal ions enter into interior zeolite-4A pores. After that the adsorption rate decreased substantially with decreasing flow rate of both metals with time. The adsorption process attained equilibrium at 160 and $200 \mathrm{~min}$ for $\mathrm{Fe}^{+}$and $\mathrm{Mn}^{2+}$, respectively. We found that the best flow rate was $20 \mathrm{ml} /$ min for both ions at which the adsorption of $\mathrm{Fe}^{2+}$ reached about $98 \%$, whereas the adsorption $\mathrm{Mn}^{2+}$ reached $100 \%$.

\section{Studies of treated columns}

\section{Breakthrough curves behaviors}

Influence of inlet flow rates on breakthrough curves The effect of flow rate for the sorption of $\mathrm{Fe}^{3+}$ and $\mathrm{Mn}^{2+}$ on to the Zeolite- $4 \mathrm{~A}$ at flow rates of 10,20 , and $30 \mathrm{~mL} / \mathrm{min}$, at an inlet concentration of $600 \mathrm{mg} / \mathrm{L}$ for $\mathrm{Fe}^{3+}$, and $1000 \mathrm{mg} /$ $\mathrm{L}$ for $\mathrm{Mn}^{2+}$ on Zeolite 4A surface at height of $12 \mathrm{~cm}$ is shown in Fig. 5. It is seen from the Figure that the rate

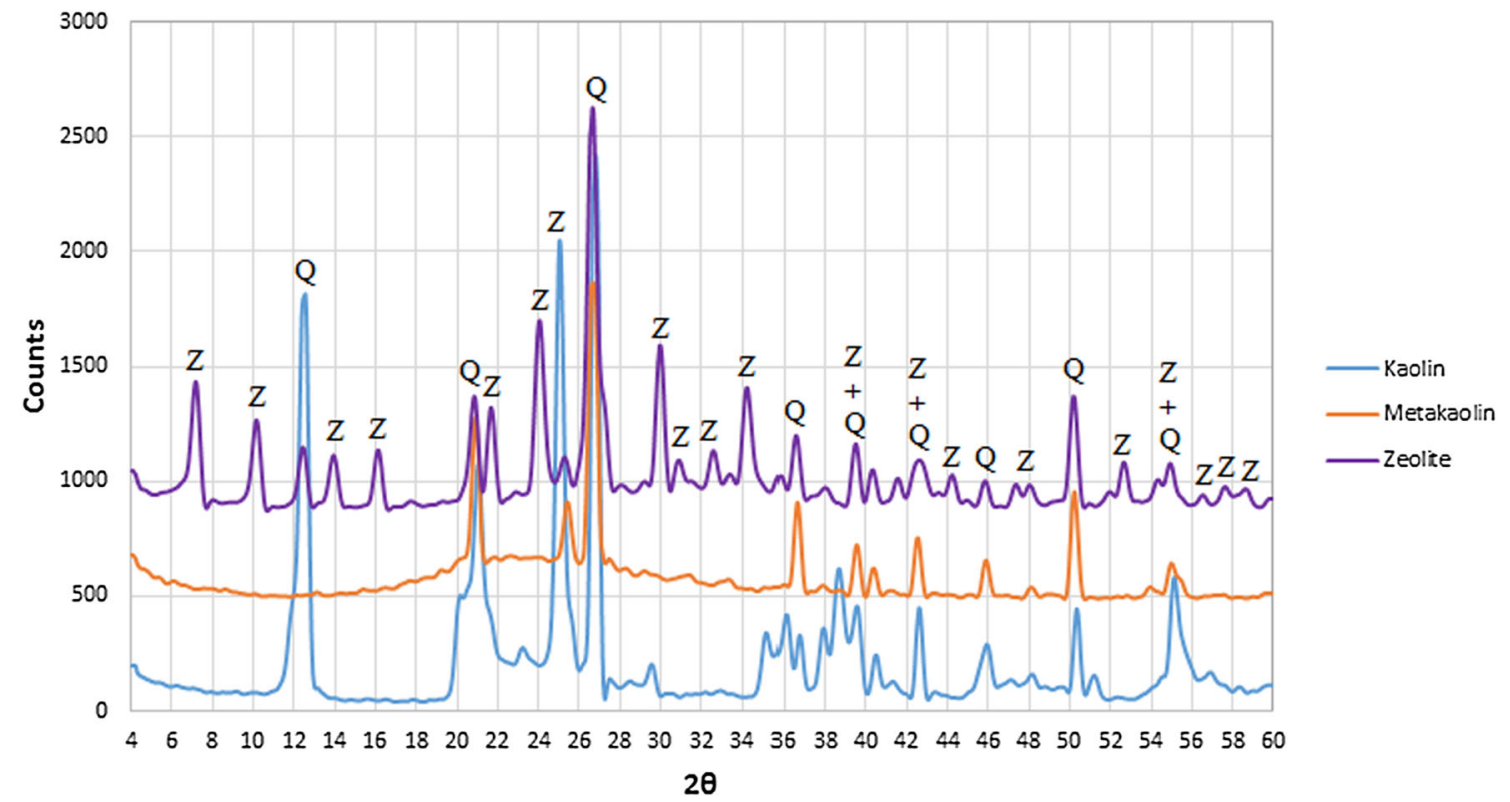

Fig. 1 XRD of zeolite-4A powder

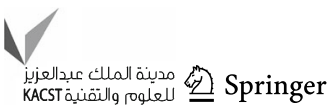



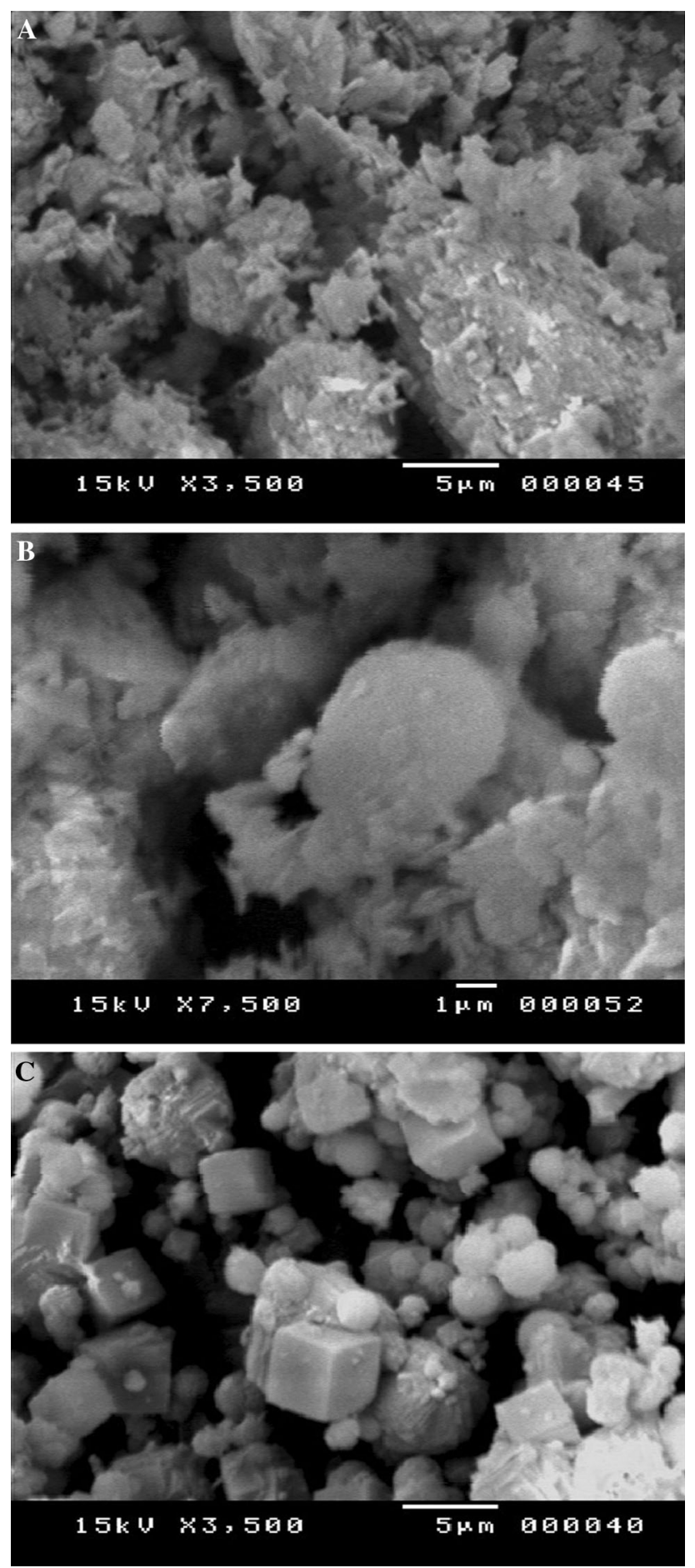

Fig. 2 a SEM micrographs of kaolinite prior to treatment. b SEM image for kaolinite after calcination. c SEM image of the final synthesized Zeolite $4 \mathrm{~A}$ crystals

sorption of $\mathrm{Fe}^{2+}$ and $\mathrm{Mn}^{2+}$ is rapid in the initial stages, decreased for $\mathrm{Mn}^{2+}$ adsorption at flow rate of $20 \mathrm{~mL} / \mathrm{min}$, and increased with respect to $\mathrm{Fe}^{2+}$ at $30 \mathrm{ml} / \mathrm{min}$ flow rate and thereby reached saturation finally after $200 \mathrm{~min}$ (Zheng et al. 2015a). The achieved results agreed well with

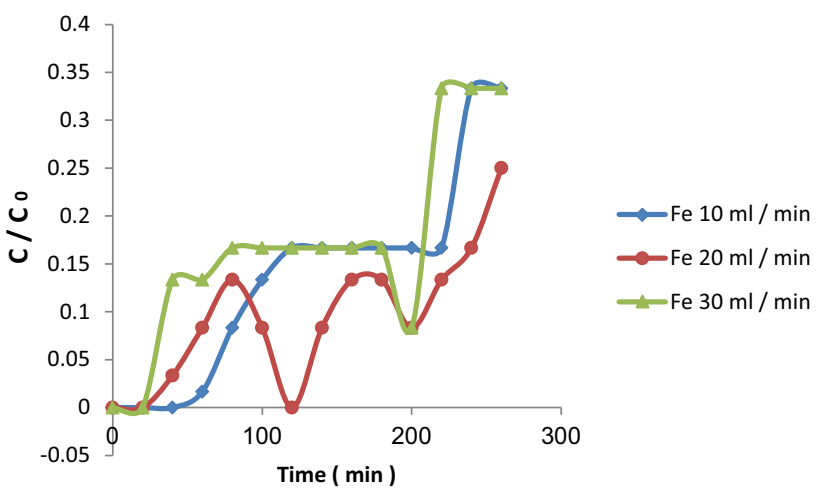

Fig. 3 Effect of contact time on the removal of $\mathrm{Fe}^{+3}$ by zeolite

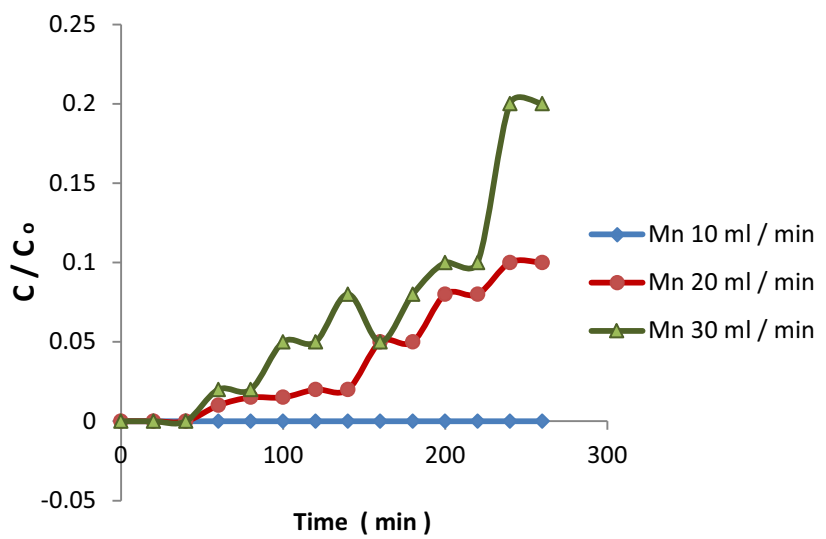

Fig. 4 Effect of contact time on the removal of $\mathrm{Mn}^{2+}$ by zeolite

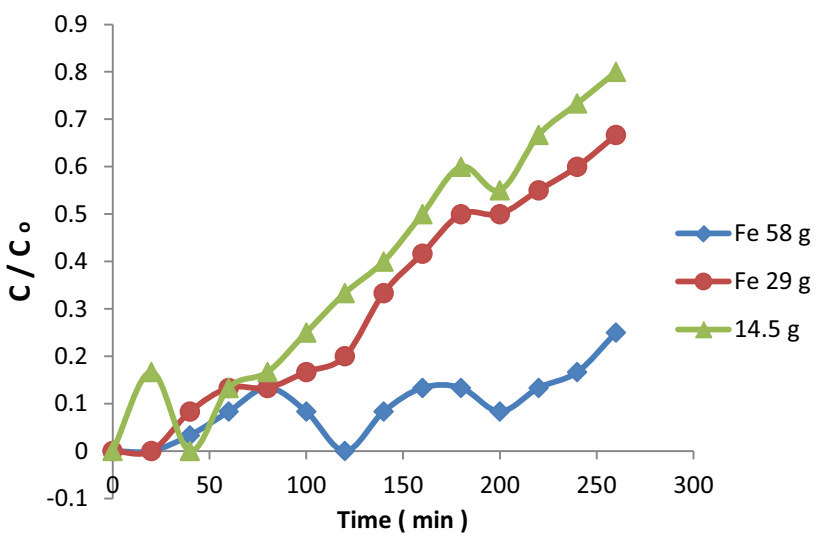

Fig. 5 Effect of zeolite height variation on the removal of $\mathrm{Fe}^{2+}$

the results obtained from the column studies; it can also be seen from Fig. 5 that the breakthrough occurred at a comparatively faster rate at higher adsorbate flow rate and less time was taken to reach the saturation breakthrough. This can be explained from the mass transfer vicinity: the rate of mass transfer is increased at higher flow rate leading to faster saturation (Beheshti et al. 2016). 


\section{Effect of zeolite- 4 A column height}

Figures 5 and 6 show the breakthrough curves obtained for adsorption of $\mathrm{Fe}^{2+}$ and $\mathrm{Mn}^{2+}$ with adsorbate inlet concentration of 300 and $1000 \mathrm{mg} / \mathrm{L}$, respectively, on zeoliteA4. Three different bed heights of 1.5, 0.75, and 0.37 at two different flow rates of 30 and $20 \mathrm{~mL} / \mathrm{min}$ for $\mathrm{Fe}^{2+}$ and $\mathrm{Mn}^{2+}$, respectively, were studied.

From the plots (Fig. 6), it is noticed that both the breakthrough time, $t b$, and exhaustion time, $t e$, were found to increase with increasing zeolite-A4 height (Amirnia et al. 2016). The plot shows that the shape and gradient of the breakthrough curves were slightly different with the variation of zeolite-A4 depth. Higher uptake and mass transfer was observed at higher zeolite-A4 height due to the increase in the amount of the latter which provided to have the ability of more fixations of the cations with active binding sites for the adsorption process to proceed (ElBahy and El-Bahy 2016). Hence, for same influent concentration and fixed zeolite-A4 system, an increase in zeolite-A4 height would create a longer distance for the mass transfer zone to reach the exit subsequently resulting in an extended breakthrough time (Han et al. 2016). For higher zeolite-A4 depth, the increase of adsorbent mass would provide a larger surface area leading to an increase in the volume of the treated underground water.

\section{Regeneration process for zeolite media}

Regeneration of the zeolite media filter in the pilot process, between iron and manganese removal cycles, was effectively achieved by contacting the zeolite media on $10 \%$ of a commercial $\mathrm{NaCl}$ solution. The regeneration protocol adopted to displace the iron, manganese and other cations adsorbed on the zeolite media during the groundwater water treatment cycle is shown in Fig. 6. The desorption of appreciable amounts of all four cations suggests that the regeneration technique is successful.

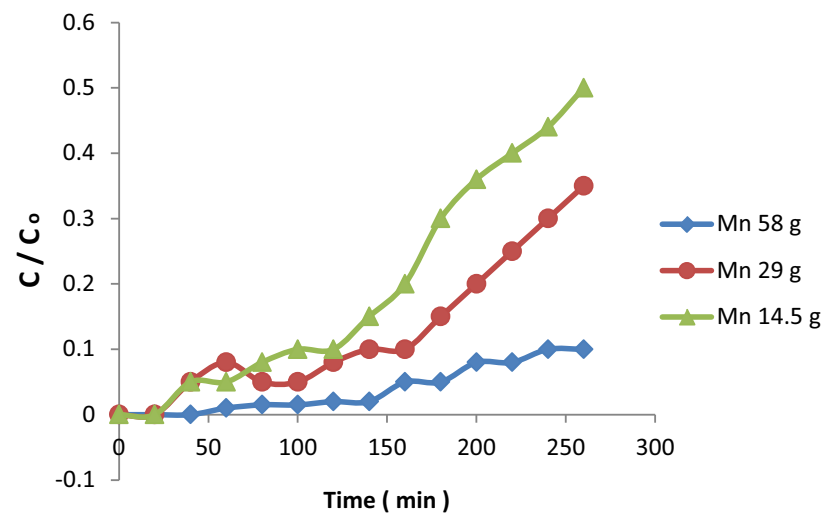

Fig. 6 Effect of zeolite height variation on the removal of $\mathrm{Mn}^{2+}$
Determination of zeolite media filter life Fifteen repetitive raw groundwater treatment cycles under identical conditions indicated the reproducibility of performance, and no deterioration of the zeolite iron and manganese exchange capacity was observed. Figure 7 and 8 show the effect of regeneration of exhausted zeolite on the removal of initial $600 \mathrm{mg} / \mathrm{L} \mathrm{Fe}^{+3}$ and $1000 \mathrm{mg} / \mathrm{L} \mathrm{Mn}^{2+}$ concentrations at three different column heights. As seen from the regeneration profiles for successive cycles of both figures a regular total mass adsorption and subsequent desorption of iron and manganese were closely matched for a series of exhaustion and desorption cycles. It may, therefore, be concluded that the quality of the zeolite as an adsorption media for iron and manganese removal from raw groundwater does not show signs of deterioration over the limited period of this study. It is anticipated that, over repeated use, the zeolite will eventually erode to some extent and the bed will require topping up. This would indicate physical deterioration or loss by attrition rather than any accumulation of cations within the zeolite particles.

\section{Breakthrough curves modeling}

In order to describe the fixed bed column behavior and to scale up for industrial applications, two models, Thomas, and Yoon-Nelson, were used to fit the experimental data in the column (Abanades et al. 2015).

Thomas model The Thomas model is widely used in performance modeling of columns. The arithmetic expression for the model of adsorption column is given in Eq. 1:

$\frac{C_{t}}{C_{0}}=\frac{1}{1+\exp \left[\left(\frac{K_{\mathrm{Th}} q_{e} x}{Q}\right)-K_{\mathrm{Th}} C_{0} t\right]}$,

where $K_{\mathrm{Th}}$ (mL/min.mg) is the Thomas model constant, $q_{e}$ $(\mathrm{mg} / \mathrm{g})$ is the predicted adsorption capacity, $x$ is mass of adsorbent ( $\mathrm{g}), Q$ is influent flow rate $(\mathrm{mL} / \mathrm{min}), C_{0}$ is initial solution concentration $(\mathrm{mg} / \mathrm{L})$, and $C_{t}$ is effluent solution concentration $(\mathrm{mg} / \mathrm{L})$. The second linear equation of Thomas model is expressed below:

$\ln \frac{C_{t}}{C_{0}}-1=\left(\frac{K_{\mathrm{Th}} q_{e} x}{Q}\right)-K_{\mathrm{Th}} C_{0} t$

From the regression coefficient $\left(R^{2}\right)$ and other parameters, it can be concluded that the experimental data fitted well with Thomas model. The model parameters are listed in Tables 1,2 and show that as the flow rate increased, the value of $k^{\text {th }}$ decreased, whereas the value of $q_{0}$ showed a reverse trend, that is, increased with increase in flow rate. Similarly, $q_{0}$ values decreased and $k^{\text {th }}$ values increased with increasing flow rate. Similar trend has also been observed for sorption of $\mathrm{Fe}^{2+}$ and $\mathrm{Mn}^{2+}$ by zeolite- 
Fig. 7 Effect of regeneration of exhausted zeolite on the removal of $\mathrm{Fe}^{2+}$ at three different column heights

Fig. 8 Effect of regeneration of exhausted zeolite on the removal of $\mathrm{Mn}^{2+}$ at three different column heights


Table 1 The values of Yoon and Nelson statistical parameter after removal of $\mathrm{Fe}^{2+}$ by zeolite

\begin{tabular}{lcll}
\hline Flow $\left(\mathrm{mL} / \mathrm{min}^{-1}\right)$ & \multicolumn{1}{l}{$K_{\mathrm{th}}$} & $R^{2}$ & $q_{0}\left(\mathrm{mg} \mathrm{g}^{-1}\right)$ \\
\hline 10 & -0.00208 & 0.998477 & 1420.04 \\
20 & 0.001846 & 0.98774 & 1555.242 \\
30 & 0.001358 & 0.980188 & 2007 \\
\hline
\end{tabular}

Table 2 The values of Yoon and Nelson statistical parameter after removal of $\mathrm{Mn}^{2+}$ by zeolite

\begin{tabular}{lcll}
\hline Flow $\left(\mathrm{mL} \mathrm{min}^{-1}\right)$ & $k_{\mathrm{th}}$ & $R^{2}$ & $q\left(\mathrm{mg} \mathrm{g}^{-1}\right)$ \\
\hline 10 & -0.00978 & 0.548826 & 840.8874 \\
20 & 0.00012 & 0.2115 & 200 \\
30 & 0.0021 & 0.45213 & 100 \\
\hline
\end{tabular}

A4 column. The good fitting of the experimental data with the Thomas model indicates that the external and internal diffusion will not be the limiting step (Bertoni et al. 2015).

Yoon-Nelson model This model is simpler than other models as it requires no data about the characteristics of the system including the type of adsorbent as well as the physical properties of the adsorption bed. The Yoon-Nelson equation is expressed as

$\frac{C_{t}}{C_{0}-C_{t}}=\exp \left(K_{Y N} t-\tau K_{Y N}\right)$,

where $K_{\mathrm{YN}}$ is the rate constant $\left(\mathrm{min}^{-1}\right)$ and $\tau$ is the time required for $50 \%$ breakthrough (min). The values of the rate constant $K_{\mathrm{YN}}$ increased with the flow rate and the initial concentration.

The Yoon-Nelson is a linear model for a single component system as expressed by : 
Table 3 The values of Yoon and Nelson statistical parameter after removing $\mathrm{Fe}^{2+}$ by zeolite

\begin{tabular}{llll}
\hline Flow $\left(\mathrm{ml} \mathrm{min}^{-1}\right)$ & $K_{\mathrm{YN}}$ & $R^{2}$ & $T$ \\
\hline 10 & $1.2 \mathrm{E}^{-05}$ & 0.93597 & 85.997 \\
20 & $11.8 \mathrm{E}^{-06}$ & 0.99918 & 79 \\
30 & $1.21 \mathrm{E}^{-05}$ & 0.98968 & 105 \\
\hline
\end{tabular}

Table 4 The values of Yoon and Nelson statistical parameter after removing $\mathrm{Mn}^{2+}$ by zeolite

\begin{tabular}{llll}
\hline Flow $\left(\mathrm{mL} \mathrm{min}^{-1}\right)$ & $K_{\mathrm{YN}}$ & $R^{2}$ & $T$ \\
\hline 10 & $2.6 \mathrm{E}^{-05}$ & 0.60839 & 268.71 \\
20 & $10.4 \mathrm{E}^{-06}$ & 0.7921 & 437.25 \\
30 & 0.0158 & 0.8971 & 207 \\
\hline
\end{tabular}

$\ln \frac{C_{t}}{C_{0}-C_{t}}=K_{Y N} t-\tau K_{Y N}$

A model based on the assumption that the rate of decrease in the probability of adsorption of adsorbate molecule and the adsorbate breakthrough on the adsorbent is proportional to the probability of the adsorbate adsorption.

The values of $K_{\mathrm{YN}}$ and $\tau$ along with other statistical parameter are listed in Tables 3, 4. It is seen from the Tables that the values of $\tau$ obtained by the model are not close to the experimental results. Thus, this model is not suitable for our case. This due to that the values of $K_{\mathrm{YN}}$ were found to decrease with decreasing the flow rate, whereas the corresponding values of $\tau$ increased with increasing flow rate. A similar trend was followed for sorption of $\mathrm{Fe}^{2+}$ and $\mathrm{Mn}^{2+}$ for zeolite-A4 column sorption.

\section{Conclusion}

The removal efficiency of iron and manganese from underground water on synthetic zeolite-A4 filter were studied. It was found that $30 \mathrm{~mL} / \mathrm{min}$ is the best flow rate for removal about $98 \%$ of iron. Meanwhile, the manganese removal efficiency reaches to $100 \%$ at optimum flow rate of $20 \mathrm{~mL} / \mathrm{min}$. The well-fitting of the experimental data with the Thomas model indicates that the external and internal diffusion will not be a limiting factor. The values of $\tau$ obtained by the Yoon and Nelson model did not fit within our experimental results, indicating that their Model did not fit with the flow rate. From this study, we can conclude that the zeolite-A4 can be used as sorbent filter for underground water polluted with $\mathrm{Fe}^{2+}$ and $\mathrm{Mn}^{2+}$.
Acknowledgments Atef M. Gad would like to thank first of all my supervisors Prof. Dr. Abdel Hay Ali Farrag, Geology Department, Assiut University and Prof. Dr. Thanaa Abdel Moghny, Applications Department, Egyptian Petroleum Research Institute.

Atef M. Gad give very special thanks to Ch. Muhammad Atef, Ch. Esslam M. Hassanin,Ch. Shimaa Abdo, Ch. Hanaa Safwat, Ch. Radwa M. Abbas, Ch. Azza M.M. Ibraheem, my colleagues, for their very effective support in preparing the diagrams, and experimental studies.

Thanks are forwarded to the entire Laboratories Sector staff of Assiut and new valley company for water and waste water for using the facilities of the Laboratories Tools.

Open Access This article is distributed under the terms of the Creative Commons Attribution 4.0 International License (http:// creativecommons.org/licenses/by/4.0/), which permits unrestricted use, distribution, and reproduction in any medium, provided you give appropriate credit to the original author(s) and the source, provide a link to the Creative Commons license, and indicate if changes were made.

\section{References}

Abanades $\mathrm{JC}$ et al (2015) Emerging $\mathrm{CO}_{2}$ capture systems. Int $\mathrm{J}$ Greenh Gas Control 40:126-166

Al-Hobaib AS, Al-Sheetan KhM, El Mir L (2016) Effect of iron oxide nanoparticles on the performance of polyamide membrane for ground water purification. Mater Sci Semicond Process 42(Part 1): $107-110$

Amirnia Shahram, Ray Madhumita B, Margaritis Argyrios (2016) Copper ion removal by Acer saccharum leaves in a regenerable continuous-flow column. Chem Eng J 287:755-764

Antunes Vanessa et al (2016) Calcium sulfate fillers and binders in Portuguese 15th and 16th centuries: ground layers from a family painting workshop-study by multianalytical spectroscopic techniques. Microchem J 125:290-298

Beheshti Hoda et al (2016) Removal of Cr (VI) from aqueous solutions using chitosan/MWCNT/Fe3O4 composite nanofibersbatch and column studies. Chem Eng J 284:557-564

Bertoni Fernando A et al (2015) Application of green seaweed biomass for MoVI sorption from contaminated waters. Kinetic, thermodynamic and continuous sorption studies. J Colloid Interface Sci 446:122-132

Bilal Muhammad et al (2013) Waste biomass adsorbents for copper removal from industrial wastewater-a review. J Hazard Mater 263(Part 2):322-333

El-Bahy Salah M, El-Bahy Zeinhom M (2016) Synthesis and characterization of polyamidoxime chelating resin for adsorption of $\mathrm{Cu}(\mathrm{II}), \mathrm{Mn}$ (II) and $\mathrm{Ni}(\mathrm{II})$ by batch and column study. J Environ Chem Eng 4(1):276-286

Han Weijiang et al (2016) Studies on the optimum conditions using acid-washed zero-valent iron/aluminum mixtures in permeable reactive barriers for the removal of different heavy metal ions from wastewater. J Hazard Mater 302:437-446

Korany EA, Tempel RN, Gomaa MA, Mohamed RG (2013) Detecting the roles of the physiochemical processes on groundwater evolution, Assiut area, Egypt-applications of hydrogeochemical and isotopic approaches. Egypt J Geol 57(2013):63-83

Loiland Jason A, Lobo Raul F (2015) Oxidation of zeolite acid sites in $\mathrm{NO} / \mathrm{O}_{2}$ mixtures and the catalytic properties of the new site in NO oxidation. J Catal 325:68-78

Obiri-Nyarko Franklin et al (2015) Geochemical modelling for predicting the long-term performance of zeolite-PRB to treat 
lead contaminated groundwater. J Contam Hydrol 177-178: $76-84$

Oliveira Barud HG et al (2015) Preparation and characterization of a bacterial cellulose/silk fibroin sponge scaffold for tissue regeneration. Carbohydr Polym 128:41-51

Ortiz-Iniesta María Jesús, Melián-Cabrera Ignacio (2015) Fenton chemistry-based detemplation of an industrially relevant microcrystalline beta zeolite. Optimization and scaling-up studies. Microporous Mesoporous Mater 206:58-66

Ozekmekci Mehtap, Salkic Gozde, Fellah Mehmet Ferdi (2015) Use of zeolites for the removal of $\mathrm{H}_{2} \mathrm{~S}$ : a mini-review. Fuel Process Technol 139:49-60

Russo AV, Domé Lobo DN, Jacobo SE (2015) Removal of MTBE in columns filled with modified natural zeolites. Procedia Mater Sci $8: 375-382$

Shankar Shiv, Rhim Jong-Whan (2015) Amino acid mediated synthesis of silver nanoparticles and preparation of antimicrobial agar/silver nanoparticles composite films. Carbohydr Polym 130:353-363

Yang Lan et al (2015) Material prepared from drinking waterworks sludge as adsorbent for ammonium removal from wastewater. Appl Surf Sci 330:228-236

Zhang Yuanbo et al (2016) Reduction behavior of SnO2 in the tinbearing iron concentrates under $\mathrm{CO}-\mathrm{CO}_{2}$ atmosphere. Part II: effect of quartz. Powder Technol 291:337-343

Zheng Changping et al (2015a) Structural characterization of a polysaccharide from Chrysanthemum morifolium flowers and its antioxidant activity. Carbohydr Polym 130:113-121

Zheng Weihong et al (2015b) CaO- $\mathrm{MgO}-\mathrm{Al}_{2} \mathrm{O}_{3}-\mathrm{SiO}_{2}$ glass-ceramics from lithium porcelain clay tailings for new building materials. J Non-Cryst Solids 409:27-33 